\title{
Hemostasis during cold dissection tonsillectomy: Comparing the use of adrenaline and normal saline
}

\author{
Adoga A. A. ${ }^{1 \star}$ and Okeke E. D. ${ }^{2}$ \\ ${ }^{1}$ Department of otorhinolaryngology, Faculty of Medical Sciences, University of Jos, Plateau State, Nigeria. \\ ${ }^{2}$ Victoria Memorial Hospital, 26D, Ibrahim Taiwo road, Jos, Plateau State, Nigeria.
}

Accepted 25 October, 2011

\begin{abstract}
Various hemostatic agents and techniques have been used to reduce intraoperative and postoperative hemorrhage in tonsillectomy. This study aims to compare the effect of using adrenaline and normal saline in maintaining hemostasis during cold dissection tonsillectomy. This is a prospective randomized single-blind study spanning fifty seven months in a private hospital setting in Jos, Plateau State, Nigeria. Thirty seven patients aged between 2 and 31 years had tonsillectomy consisting of 22 $(59.5 \%)$ males and $15(40.5 \%)$ females. The mean age of patients was 15.6 years $(S D= \pm 8.97)$. Recurrent tonsillitis $(45.9 \%)$ was the commonest indication for surgery and obstructive sleep apnea was the commonest associated indication in $12(32.4 \%)$ patients. In $12(32.4 \%)$ patients, there was no associated indication for surgery. The mean time required to achieve hemostasis with the use of adrenaline soaked gauze compress was $3.84 \mathrm{~min}$. $(S D= \pm 0.92)$ and with the normal saline soaked gauze compress was $4.15 \mathrm{~min}$. $(S D= \pm 0.81)$ with a difference of $0.31 \mathrm{~min}$. There was no incidence of primary, reactionary or secondary hemorrhage. The local application of adrenaline as a topical hemostatic agent during tonsillectomies is effective in reducing intraoperative and postoperative hemorrhage and invariably reducing operative time with no significant side effects or complications.
\end{abstract}

Key words: Tonsillectomy, hemostasis, Nigeria.

\section{INTRODUCTION}

Tonsillectomy is one of the commonest surgical procedures performed by otolaryngologists worldwide and various techniques have been developed with each one seeking to ensure a reduction in the postoperative morbidity and complications of the procedure (Pinder and Hilton, 2001; Gendy et al., 2005). As at this time, no technique has been found to be more superior to the other (Leach et al., 1993). It is a procedure usually but not always done with adenoidectomies.

Hemorrhage is one of the most important complications of tonsillectomy and this could be primary, reactionary or secondary. To avoid this complication, proper preoperative preparation of patients is essential by proper history taking, clinical examination and investigations to rule out

\footnotetext{
${ }^{\star}$ Corresponding author. E-mail: adeyiadoga@gmail.com
}

bleeding disorders in patients and those to ensure patients are optimized for the procedure.

Controversies exist in the preoperative evaluation of patients for tonsillectomy especially regarding hemorrhage and its control (Bolger et al., 1990; Gabriel et al., 2000; Asaf et al., 2001) but this paper would not dwell on these issues.

A number of techniques are used to control hemorrhage during cold dissection tonsillectomy ranging from the application of adrenaline soaked gauze pressure packs on the tonsillar fossa, the application diathermy and ligatures to bleeding vessels to newer methods like the use of the Ligasure Vessel Sealing System (LVSS) and the Ankaferd Blood Stopper (Prokopakis et al., 2005; Teker et al., 2009). These newer techniques have been found to be safe and efficient, reducing intraoperative bleeding and operative time as compared to the older traditional hemostasis methods (Prokopakis et al., 2005; 
Table 1. Age distribution of patients who had tonsillectomy.

\begin{tabular}{ccc}
\hline Age & Frequency & Percentage \\
\hline $1-10$ & 11 & 29.7 \\
$11-20$ & 14 & 37.9 \\
$21-30$ & 11 & 29.7 \\
$31-40$ & 1 & 2.7 \\
Total & 37 & 100 \\
\hline
\end{tabular}

Teker et al., 2009).

Side effects to high doses of adrenaline such as sinus tachycardia have been reported but its use in diluted concentrations such as $1: 200,000$ is quite beneficial as a hemostatic agent during tonsillectomy (Rasgon et al., 1991; Bachmann et al., 1988). It is the adequate control of intraoperative hemorrhage that precludes reactionary and secondary hemorrhages from occurring thereby ensuring a safer and better outcome for the patients post tonsillectomy.

\section{PATIENTS AND METHODS}

This is a prospective randomized single-blind study spanning fifty seven months (April 2006 to December 2010) carried out in a private hospital in Jos, Nigeria. Consent was obtained from all the patients or their parents in the case of minors.

Thirty seven patients were drawn from the pool presenting to our private hospital with tonsillitis within the study period following approval by the ethical committee of the hospital.

The inclusion criteria were;

1. Patients with tonsillitis unresponsive to medical treatment.

2. Patients with three or more episodes of tonsillitis in the past year.

3. Patients with tonsil hypertrophy and snoring or obstructive sleep apnea.

Patients with bleeding disorders, on aspirin and those with unilateral tonsil enlargement were excluded from this study.

Preoperatively, patients had routine blood investigations which include Full Blood Count (FBC), Prothrombin/Partial Thromboplastin Time (PT/PTT).

Patients were randomized into two groups, one consisting of 18 patients and the other 19. All patients had cold dissection tonsillectomy. The first group had adrenaline (1:200,000 dilution) gauze compress applied to their right tonsils during tonsillectomy, normal saline compress to the left tonsils and vice versa in the second group. Patients were monitored intraoperatively for the side effects of adrenaline use.

Each patient was given parenteral amoxicillin and paracetamol postoperatively. The variables recorded in this study were the age and gender of the patients, the indications and associated indications for tonsillectomy, the time taken to achieve hemostasis using adrenaline and normal saline (control) and the postoperative complications. The time taken to achieve hemostasis was recorded as the time from commencement of dissection to stoppage of hemorrhage on the operated side.

The data collected was analyzed using EPI-INFO database and statistical software for public health professionals' version 3.5.1.

\section{RESULTS}

Thirty seven patients were drafted into this study consisting of $22(59.5 \%)$ males and $15(40.5 \%)$ females, aged between 2 and 31 years, giving a male to female ratio of $1.5: 1$. The mean age of patients was 15.6 years $(\mathrm{SD}= \pm 8.97$ ).

Patients in the age groups 11 to 20 years constituted the majority (Table 1$)$. Recurrent tonsillitis (45.9\%) was the commonest indication for surgery and obstructive sleep apnea was the commonest associated indication in $12(32.4 \%)$ patients. In 12 (32.4\%) patients, there was no listed associated indication for surgery (Figures 1 and 2). The mean time required to achieve hemostasis with the use of adrenaline soaked gauze compress was $3.84 \mathrm{~min}$. $(\mathrm{SD}= \pm 0.92)$ and with the normal saline soaked gauze compress was $4.15 \mathrm{~min}$. (SD $= \pm 0.81)$ with a difference of 0.31 min. $(p=0.05)$.

There was no incidence of primary, reactionary or secondary hemorrhage in our series. All the patients were discharged home on the second postoperative day with an outpatient clinic review on the fifth postoperative day and no significant postoperative sequele.

\section{DISCUSSION}

Hemorrhage is a frequent and often the most dreaded complication of tonsillectomy. This has prompted the use of a variety of topical haemostatic agents such as bismuth subgallate and adrenaline to achieve hemostasis and reduce the risk of intra and postoperative hemorrhage (Rasgon et al., 1991; Agrawal et al., 2005; Sharma et al., 2007).

Although the conventional techniques for securing hemostasis like ligation and/or cauterization control the major bleeders yet occasionally the diffuse bleeding and capillary oozing may pose difficulty for the surgeon to locate the bleeders, contribute to inefficient hemostasis and in turn enhance blood loss and prolong operation time (Callanan et al., 1995).

Adrenaline which is the commonly used topical hemostatic agent in our region is a powerful vasoconstrictor producing retraction of blood vessels in the tonsillar bed. Adrenaline also promotes platelet aggregation in the formation of blood clot. It has been demonstrated by Hatton to be inexpensive, posing little risk, decreasing intraoperative bleeding, therefore being a reasonable hemostatic agent (Hatton, 2000). These characteristics especially the decrease in intraoperative bleeding and invariably decrease in intraoperative time is demonstrated in our study.

The commonest indication for tonsillectomy in our series is recurrent tonsillitis with the commonest associated indication being obstructive sleep apnea (OSA). These are absolute indications for tonsillectomy and correspond to the findings in other series (Darrow and Siemens, 2002; Jurado Ramos et al., 2006; Mora et al., 2003). Snoring ranks next to OSA as an associated indication in our study. Sometimes primary snoring and OSA overlap and only polysomnography can differentiate 


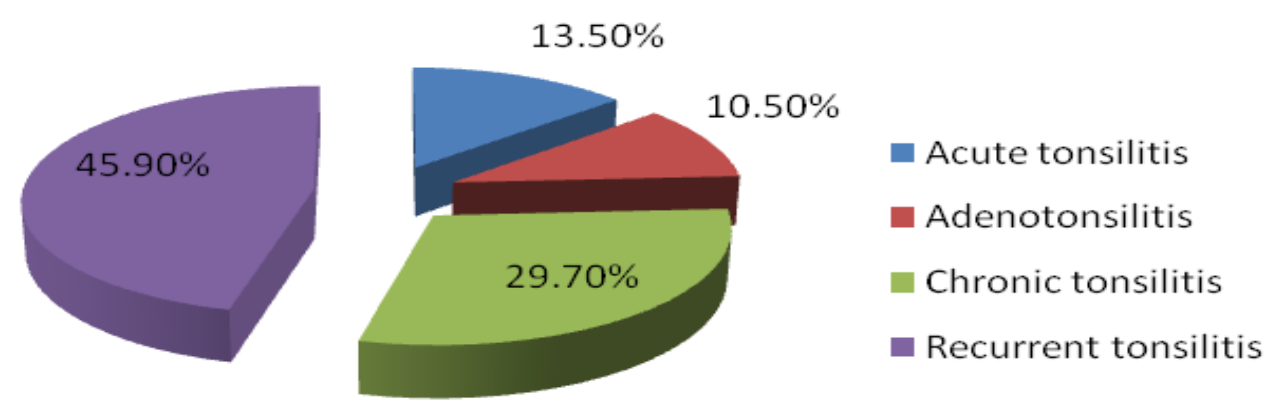

Figure 1. Primary indications for tonsillectomy.

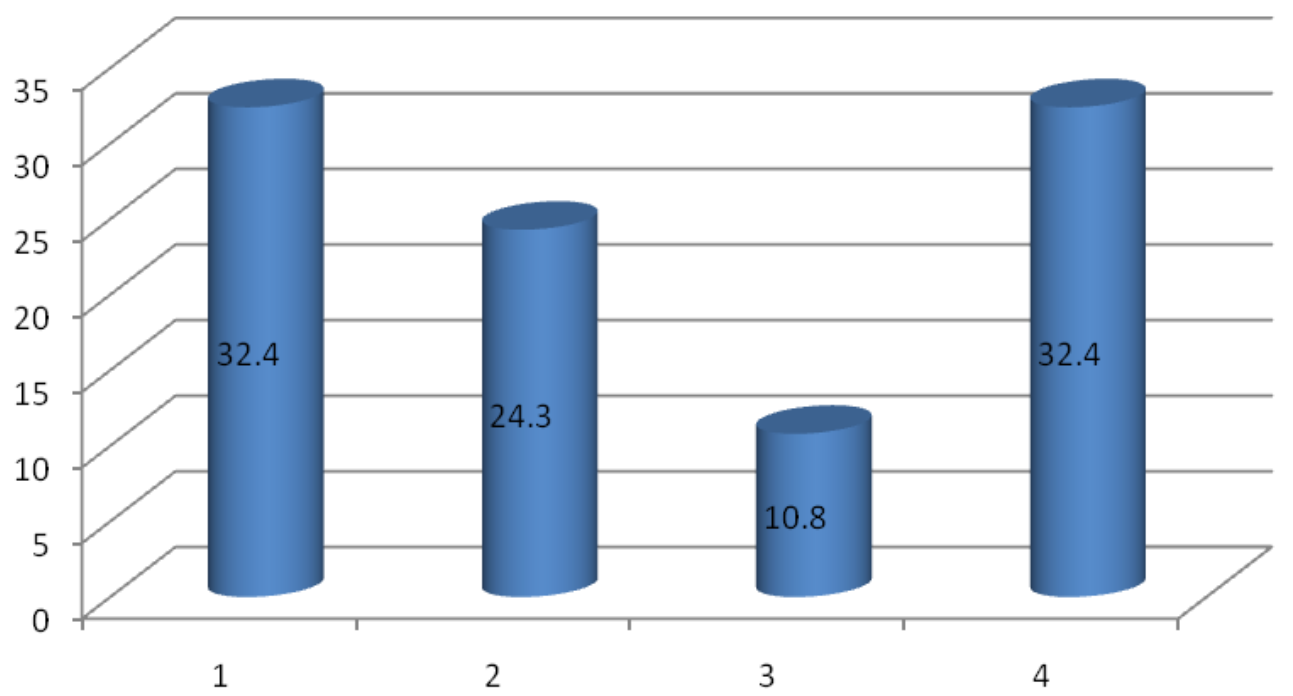

Figure 2. Associated indications for tonsillectomy.

Key: 1 = Obstructive sleep apnea; 2 = Snoring; $3=$ Otitis media with effusion; $4=$ None.

the two disorders. The use of polysomnography is complex, highly controversial and expensive (Ameli et al., 2007). There is no center from this part of the world with specialized diagnostic facilities like polysomnography so we resort to performing tonsillectomy on the patients who presented with features of tonsillitis, snoring and obstructive sleep apnea.

In accordance with other studies, we observed an improvement in the time required for the achievement of hemostasis with the use of adrenaline (Rasgon et al., 1991; Sharma et al., 2007).

Our study shows that adrenaline compared to the use of saline produced significant difference in hemostasis time. However, saline itself has also been shown to have an effect on hemostasis (Candan et al., 1992). The side effects of adrenaline include a rise in blood pressure, tachycardia and even cardiac dysrhythmias. These effects usually occur following intravascular injection, are transient lasting between 3.5 to $4 \mathrm{~min}$. and are due to the actions of adrenaline on Beta2 adrenoceptors. These side effects were not noted in any of our patients intraoperatively. This may probably be as a result of the high dilution of adrenaline used.

We did not record any case of postoperative hemorrhage. This could be attributed to our strict adherence to meticulous dissection and proper control of hemorrhage intraoperatively.

This study has therefore demonstrated that local use of adrenaline in tonsillectomy is safe and effective in reducing the incidence of perioperative hemorrhage. However, gauze soaked in normal saline can also be used to achieve hemostasis during tonsillectomy with favorable post-operative outcome.

\section{Conclusion}

The local application of adrenaline as a topical hemostatic agent during tonsillectomies is effective in reducing intraoperative and postoperative hemorrhage and invariably reducing operative time with no significant side effects or complications. 


\section{REFERENCES}

Agrawal SR, Jain AK, Marathe D, Agrawal R (2005). The effect of bismuth subgallate as hemostatic agent in tonsillectomy. Indian J. Otolaryngol. Head Neck Surg., 57(4): 287-289.

Ameli F, Brocchetti F, Semino L, Fibbi A (2007). Adenotonsillectomy in obstructive sleep apnea syndrome. Proposal of a surgical decision taking algorithm. Int. J. Pediatr. Otorhinolaryngol., 71(5): 729-34.

Asaf T, Reuveni H, Yermiahu $T$ (2001). The need for routine preoperative coagulation screening tests (prothrombin time PT/ partial thromboplastin time PTT) for healthy children undergoing elective tonsillectomy and/or adenoidectomy. Int. J. Pediatr. Otorhinolaryngol., 61(3): 217-22.

Bachmann B, Biscoping J, Adams HA, Sokolovski A, Ratthey K, Hempelmann G (1988). Plasma concentrations of lidocaine and prilocaine following anesthesia in otorhinolaryngologic surgery. Laryngol. Rhinol. Otol., 67(7): 335-9.

Bolger WE, Parsons DS, Potempa L (1990). Preoperative hemostatic assessment of the adenotonsillectomy patient. Otolaryngol. Head Neck Surg., 103(3): 396- 405.

Callanan V, Curran AJ, Smyth DA, Gormley PK (1995). The influence of bismuth subgallate and adrenaline paste upon operating time and operative blood loss in tonsillectomy. J. Laryngol. Otol., 109(3): 206208.

Candan S, Yuceturk AV, Muhtar H (1992). The effect of peritonsillar infiltration on intra-operative blood loss in children. J. Otolaryngol., 21(6): 439-40.

Darrow DH, Siemens C (2002). Indications for tonsillectomy and adenoidectomy. Laryngoscope, 112(8pt2 Suppl 100): 6-10.

Gabriel P, Mazoit X, Ecoffey C (2000). Relationship between clinical history, coagulation tests and perioperative bleeding tonsillectomies in pediatrics. J. Clin. Anesth., 12(4): 288-91.
Gendy S, O'leary M, Colreavy M, Rowley H, O'Dwyer T, Blayney A (2005). Tonsillectomy- cold dissection versus hot dissection: a prospective study. Ir. Med. J., 98(10): 243-4.

Hatton RC (2000). Bismuth subgallate-epinephrine paste in adenotonsillectomies. Ann. Pharmacother., 34(4): 522-5.

Jurado RMJ, Sagales ST, Romero SO, Pellicer SM, Pamarola SF (2006). Revision of obstructive sleep apnea syndrome in the child. An Otorrinolaringol. Ibero. Am., 33(2): 101- 21.

Leach J, Manning S, Schaefer S (1993). Comparison of two methods of tonsillectomy. Laryngoscope, 103(6): 619-22.

Mora R, Salami A, Passalli FM (2003). OSAS in children. Int. J. Pediatr. Otorhinolaryngol., 67 Suppl 1: S229-31.

Pinder D, Hilton M (2001). Dissection versus diathermy for tonsillectomy. Cochrane Database Syst. Rev., (4): CD002211.

Prokopakis EP, Lachanas VA, Benakis AA, Vardouniotis AS, Velegrakis GA (2005). Tonsillectomy using the ligasure vessel sealing system. A preliminary report. Int. J. Pediatr. Otorhinolaryngol., 69(9): 1183-6.

Rasgon BM, Crus RM, Hilsinger RL, Korol HW, Callan E, Wolgart RA (1991). Infiltration of epinephrine in tonsillectomy: a randomized, prospective double-blind study. Laryngoscope, 101(2): 114-8.

Sharma K, Kumar D, Sheemar S (2007). Evaluation of bismuth subgallate and adrenaline paste as hemostats in tonsillectomy bleeding. Indian J. Otolaryngol. Head Neck Surg., 59(3): 300-302.

Teker AM, Korkut AY, Gedikei O, Kahya V (2009). Prospective controlled clinical trial of Ankaferd Blood Stopper in children undergoing tonsillectomy. Int. J. Pediatr. Otorhinolaryngol., 73(12): $1742-5$. 